\title{
Pectoralis major-rectus abdominis bipedicled muscle flap in the treatment of poststernotomy mediastinitis
}

Tai Suk Roh, MD, Won Jai Lee, MD, PhD, Dae Hyun Lew, MD, and Kwan Chul Tark, MD

Objectives: Although the incidence of infected sternotomy wounds after median sternotomy for cardiovascular surgery is relatively low (0.5\% to 5\%), it is associated with significant morbidity and a long period of treatment. Today, muscle flaps, such as the pectoralis major or the rectus abdominis, are widely accepted as a mainstay of reconstructive options. Each method carries unavoidable limitations and setbacks of its own. To overcome the disadvantages of the pectoralis muscle and rectus abdominis muscle flaps, we designed and performed a pectoralis major-rectus abdominis muscle bipedicled flap for the coverage of sternal defects.

Methods: The pectoralis major-rectus abdominis bipedicled flap was elevated as a single unit, preserving the thoracoepigastric fascia in continuity with the rectus muscle and its anterior fascia. The method was used in 27 patients with postoperative mediastinitis during a 5-year period.

Results: The bipedicled flap could fill the defect with sufficient volume, not only in the upper two thirds but also in the lower one third of the sternum. Recurrent uncontrolled infection developed in $11 \%$ of all cases, and upper abdominal fascial attenuation was observed in 1 patient. There were no surgical intervention-related complications or deaths.

Conclusions: We conclude that pectoralis major-rectus abdominis bipedicled flap is a practical and efficacious method in the reconstruction of the anterior chest wall defect caused by poststernotomy mediastinitis. It not only provides sufficient volume to fill the entire mediastinum but also affords resolution of the infected wound with favorable outcomes comparable with those of other methods.

From the Institute for Human Tissue Restoration, Department of Plastic and Reconstructive Surgery, Yonsei University College of Medicine, Seoul, Republic of Korea.

Received for publication Oct 13, 2007; revisions received Dec 23, 2007; accepted for publication Jan 22, 2008.

Address for reprints: Won-Jai Lee, MD, Department of Plastic and Reconstructive Surgery, Yonsei University College of Medicine, 134 Shinchon-Dong, Seodaemun-Gu, Seoul, Korea (E-mail: pswjlee@yumc. yonsei.ac.kr).

J Thorac Cardiovasc Surg 2008;136:618-22 $0022-5223 / \$ 34.00$

Copyright $\odot 2008$ by The American Association for Thoracic Surgery

doi:10.1016/j.jtcvs.2008.01.044
$\mathrm{T}$ The treatment modalities for mediastinitis after sternotomy include conservative methods using open wet dressing, occlusive continuous irrigation or vacuumassisted closure, and surgical treatment with flaps of the pectoralis major, rectus abdominis, latissimus dorsi muscle, or omentum. Recently, excellent results have been reported in favor of the conservative methods, with special emphasis on vacuumassisted closure. ${ }^{1,2}$ However, the general consensus is still valid that muscle flap obliteration of dead space resulting from debridement of potentially infected tissue is essential in obtaining wound closure in a significant number of recalcitrant cases. ${ }^{3,4}$

Among the various flaps used for the treatment of mediastinitis, the pectoralis major and rectus abdominis muscles have been used most frequently because of proximity to the wound and ease of elevation. Each flap has a limitation of its own. The pectoralis fails to provide fill in the lower third of the sternum, and the rectus cannot be used freely if the ipsilateral pedicle has been used in coronary artery bypass grafting $(\mathrm{CABG}) .^{5}$ The pectoralis major-rectus abdominis bipedicled muscle flap procedure stems from an effort to overcome these problems, thus providing an adequate muscle flap alternative.

\section{Materials and methods}

Twenty-seven patients subjected to sternotomy from April 2002 through May 2007 in the Department of Thoracic Surgery at the Severance Hospital had poststernotomy mediastinitis and 


\section{Abbreviations and Acronyms}

$\mathrm{CABG}=$ coronary artery bypass grafting

MRSA = methicillin-resistant Staphylococcus aureus

were subsequently treated with bilateral pectoralis major-rectus abdominis bipedicled muscle flap procedures. According to the Pairolero and Arnold classification, the series included 5 type I, 14 type II, and 8 type III wounds at the time of presentation. In 23 patients several surgical debridements were performed before the definitive operation. Remarkable reduction in bacterial count provided an index to the timing of reconstructive surgery. In the remaining 4 patients, initial single debridement concomitant with definitive flap surgery was performed. All wirings and infected osseocartilaginous debris were removed before reconstruction, but complete sternectomy was not viewed as essential in all cases. At the completion of debridement and thorough irrigation, the resulting defect is reassessed in regard to the flap selection.

From the edge of the sternal defect, the skin and subcutaneous flap was elevated, extending to the clavicle, humeral head, and inferior intercostal margin, thus exposing the anterior surface of the pectoralis muscle. The undersurface of the pectoralis major muscle was then freed from the rib cage and its costal insertions in its entirety. Superiorly, half to two thirds of the clavicular origin was detached medial to the thoracoacromial pedicle. No additional muscle backcut was done lateral to the pedicle, and the humeral insertion was preserved. The rectus abdominis muscle, including a rectangle of its anterior fascia, was elevated from its posterior sheath to facilitate centralization of the pectoral muscle without resection of the humeral insertion. Continuity was carefully preserved from the pectoral-thoracoepigastric fascia to the anterior rectus sheath. The lateral-most costal insertions of the rectus can be detached for ease of mobilization without compromise of the flap circulation. The internal thoracic artery, when present, was preserved in the elevated rectus abdominis muscle and maintained its connection to the superior epigastric artery (Figures 1 and 2). Identical procedures were performed on the contralateral side, and both flaps were advanced medially to fill the dead space (Figure 3). The flaps were sutured securely with absorbable sutures, and a chest tube was inserted into the pleural space. Suction drains were inserted below the muscle flaps and skin flaps.

\section{Results}

Of 1362 valuloplasties, 952 CABGs, and 156 valvuloplasties concomitant with CABG performed in the time period from April 2002 through May 2007, the subjects of our study included 5 postvalvuloplasty $(0.36 \%), 21$ post-CABG (2.2\%), and 1 postvavuloplasty plus CABG (0.64\%) patients. Among the 27 patients, 15 were male and 12 were female, and their mean ages were 60.3 years and 61.2 years, respectively. The average duration between the sternotomy and the occurrence of mediastinitis was 18.3 days, and the interval from the diagnosis of mediastinitis to the flap operation was, on average, 1.1 months. The average follow-up period after the flap operation was 5 months (Table 1). With regard to the bacterial organisms cultured from the wounds, methicillin-resistant Staphylococcus aureus (MRSA) was found in 16 patients, $S$ aureus was found in 8 patients, and no organisms were detected in 3 patients (Table 1). In all patients mediastinitis invaded the lower third of the sternum, and the defect was reconstructed by using the bipedicled muscle flap. As postoperative complications, recurrent mediastinitis was detected in $3(11 \%)$ patients. Of these 3 patients, in 2 the unilateral pectoralis major muscle advancement flap operation was performed, and in 1 the rectus abdominis myocutaneous rotation flap operation was used. Superficial skin flap dehiscence of the suture site occurred in 5 patients; however, 4 patients responded to conservative treatment, and 1 patient was cured completely with vacuum-assisted closure. Upper abdominal fascial attenuation developed in 1 patient, presenting as local bulging that did not necessitate active treatment (Table 2). Postoperative complications, such as hematoma, exacerbation of the condition, or mortality caused by the operation were not observed.
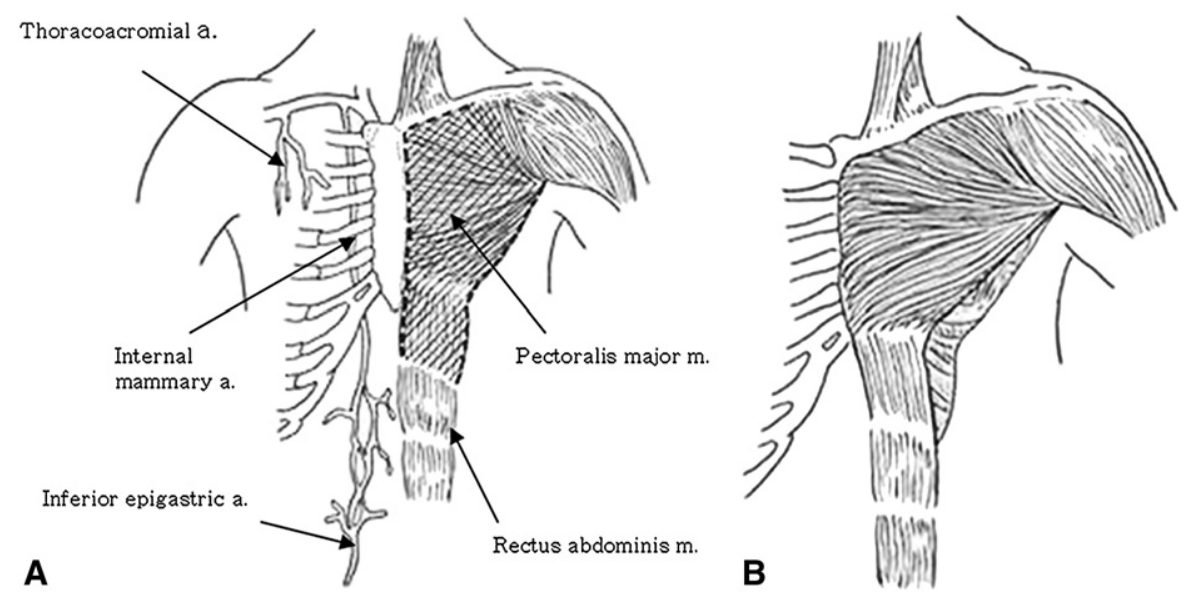

Figure 1. A, The bipedicled muscle flap consists of a superiorly based pectoralis major muscle flap and an inferiorly based rectus abdominis muscle flap raised in continuity. $B$, The flap is transposed into the defect. 

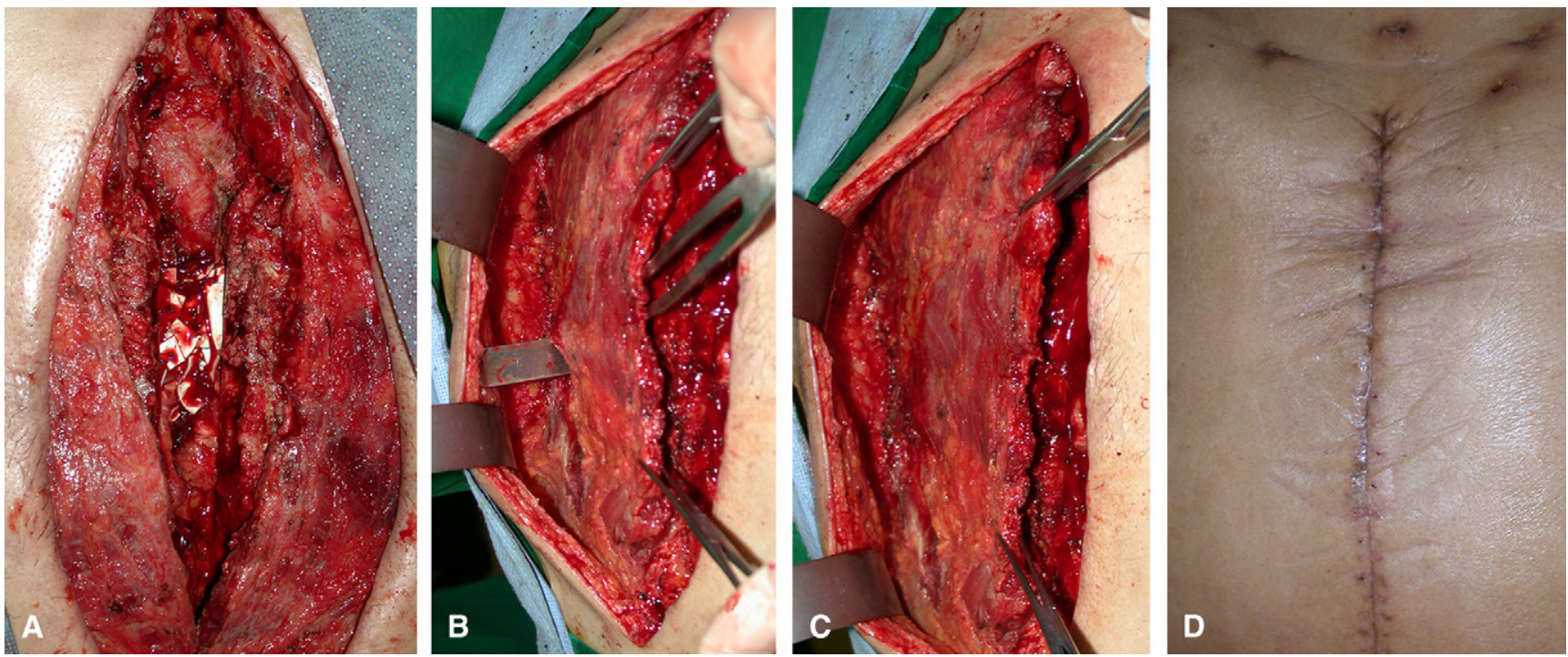

Figure 2. A, A 65-year-old man with an anterior chest wall defect caused by mediastinitis after coronary artery bypass graft surgery. B and C, The elevated bipedicled pectoralis major-rectus abdominis muscle flap. D, Four weeks' follow up.

\section{Discussion}

The therapeutic modalities for poststernotomy mediastinitis can be classified in 2 ways: conservative and surgical. Conservative treatments include administration of antibiotics, incisional drainage, frequent application of wet dressing after debridement of necrotic tissues, occlusive continuous irrigation after debridement and vacuum-assisted closure, and so on. The latter 2 treatments are actively being used with variable but successful results in many institutions as the first-line therapy. Oakely and Wright ${ }^{3}$ advocated conservative therapy
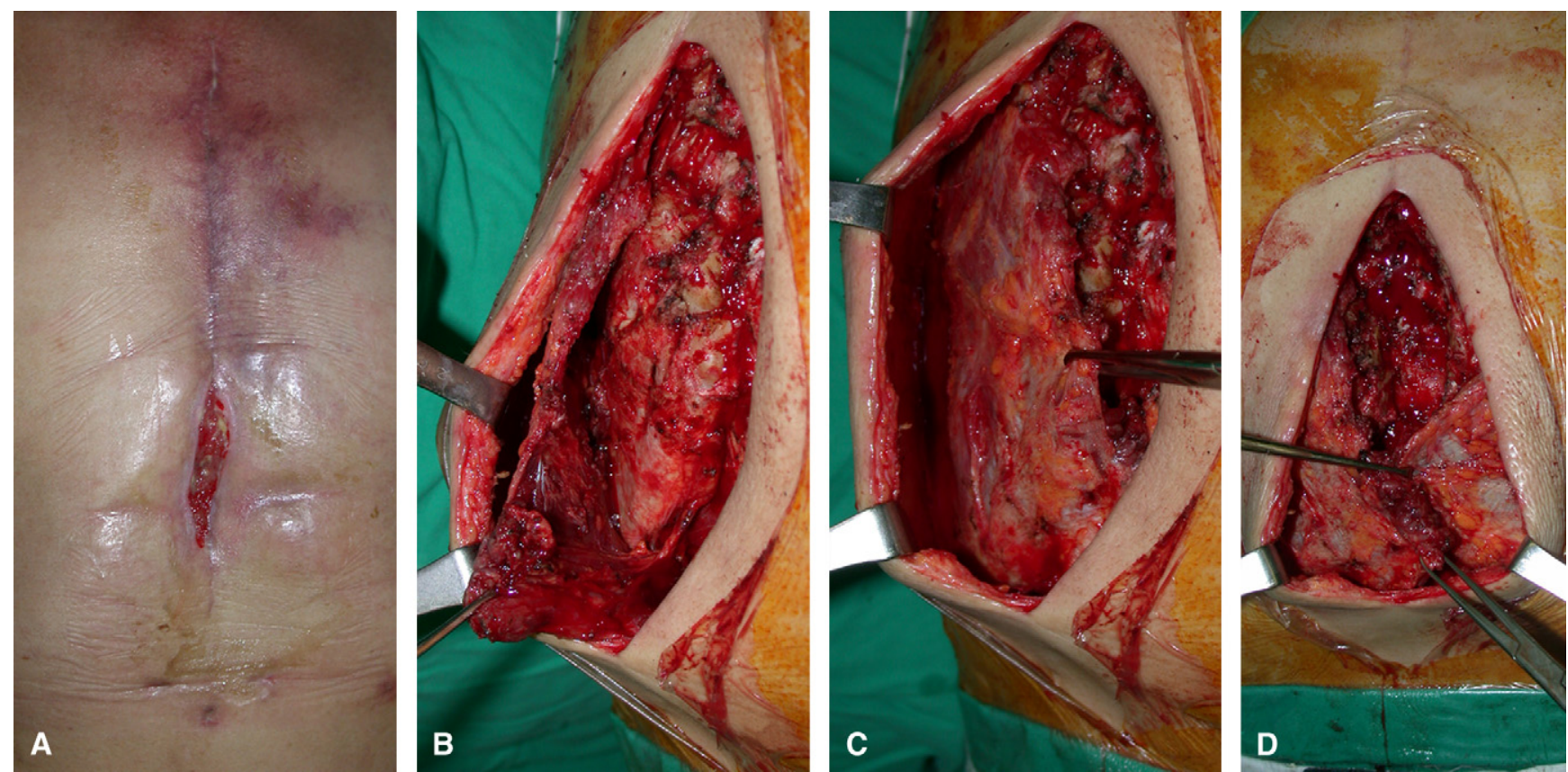

Figure 3. A, A 51-year-old man with an anterior chest wall defect caused by mediastinitis after valve replacement surgery. B and C, The elevated bipedicled pectoralis major-rectus abdominis muscle flap. D, The bilateral flap units are transposed medially and cover the lower third of the defect of the anterior chest. 


\section{TABLE 1. Patient characteristics}

\begin{tabular}{lc} 
Total no. of patients (male/female) & $17(15 / 12)$ \\
Mean age (y) & 61 (19-77) \\
Preoperative diagnosis & 21 \\
CAOD & 5 \\
Valve disease & 1 \\
CAOD + valve disease & 18.3 \\
Mean interval from cardiac surgery to symptom & \\
$\quad$ development of mediastinitis (d) & 1.1 \\
Mean interval from the diagnosis of infection to & \\
flap operation (mo) & 5 \\
Average follow-up duration after flap operation (mo) & \\
Microorganisms & 16 \\
$\quad$ MRSA & 8 \\
$\quad$ MSSA & 3 \\
$\quad$ No growth & \\
\hline CAOD, Coronary artery occlusive disease; MRSA, methicillin-resistant \\
Staphylococcus aureus; MSSA, methicillin-susceptible Staphylococcus \\
aureus.
\end{tabular}

of wound debridement and mediastinal irrigation alone as being the ideal therapy in their classification of type I mediastinitis presenting within 2 weeks after surgical intervention in the absence of risk factors. This was no different from our experience in some of our earlier cases. However, because our cardiothoracic service is a tertiary referral center, the large number of patients presenting with risk factors, such as obesity and diabetes, together with the high proportion of bacterial isolation of virulent and persistent organisms, such as MRSA, mandated a more active approach to surgical intervention. It has been well documented that the clinical outcome of poststernotomy mediastinitis caused by MRSA is poor, with significantly higher morbidity and mortality. ${ }^{6,7}$ In fact, Hirata and associates ${ }^{8}$ have treated MRSA-associated mediastinitis as a different entity with potentially devastating complications. In their report 4 cases of MRSA-associated mediastinitis were treated by means of early radical debridement followed by omental transposition in a single procedure. This view has been supported by Jones and colleagues $^{9}$ in a large retrospective study reporting their experience with use of the single-stage muscle flap procedure

\section{TABLE 2. Complications}

\begin{tabular}{lrl}
\hline \multicolumn{1}{c}{ Complication } & & \multicolumn{1}{c}{ Treatment } \\
\hline None & 20 & \\
Recurrence & 3 & $\begin{array}{l}\text { Uni PM adv: } 2 \\
\text { RA: } 1\end{array}$ \\
Focal dehiscence & 3 & $\begin{array}{l}\text { Conservative management 2 } \\
\text { VAC device: } 1 \\
\text { Observation }\end{array}$ \\
Fascial attenuation & 1 & Obs
\end{tabular}

Uni PM adv, Unilateral pectoralis major muscle flap; $R A$, vertical rectus abdominis muscle flap; VAC, vacuum-assisted closure. for infected median sternotomy wounds. In a similar context, although the effectiveness of vacuum-assisted closure is fully realized, we were forced to view such conservative measures as a bridge step in preparation for definitive flap surgery rather than as the final curative tool. ${ }^{8}$ Our average duration from the diagnosis of mediastinitis to operative intervention, 1.1 months, supports this sequence of approach.

In the selection of a reconstructive flap ideally suited to each clinical setting, various factors must be taken into consideration. These include the location and size of the defect, the medical and surgical history of the patient, and the preference of the surgeon. Prior abdominal operations, such as cholecystectomy and coronary artery bypass surgery with the internal thoracic artery or the gastroepiploic artery, represent examples of limited flap choice because of the anatomic factors related to the operation. ${ }^{3,5}$

The advantage of the pectoralis major muscle flap lies in the ability to raise the flap from the existing edge of the opened wound. However, it sometimes falls short of filling the entire defect, especially in the lower third of the sternum. Moreover, if the internal thoracic artery was sacrificed during the previous coronary artery bypass surgery, it cannot be used as a turnover flap. Resection of the humeral insertion of the pectoralis major muscle to facilitate flap advancement results in loss of the anterior axillary fold. Limitation of shoulder motion, weakening of muscle strength, pain, and paresthesia are additional comorbidities from such procedures. ${ }^{10}$ The rectus abdominus muscle flap is known to fit ideally in the lower third of the sternal defect. However, mobilization of the internal thoracic artery for coronary artery bypass precludes its use. The use of the rectus abdominis muscle turnover flap based on the intercostal artery ${ }^{11}$ has limited use because of its small rotation arc. The omental flap is the most superior choice in terms of controlling the infection because of its abundant lymphoid tissues and the ability to regenerate blood vessels. However, among several known drawbacks of the omental transfer, the most concerning is the need for open abdominal surgery and the risk for intraperitoneal spread of infection. $^{12}$

The pectoralis major and rectus abdominis muscles are connected by a fascia. It has been shown that this fascia plays a role not only as a mechanical linker but also as a conduit for blood flow between these 2 muscles. ${ }^{13,14}$ Hence by virtue of such a feature, these 2 muscles can be elevated as a single unit, the pectoralis major-rectus abdominis bipedicled flap, maintaining the thoracoepigastric fascia. This flap can fill the whole defect with sufficient volume, not only in the upper two thirds but also in the lower third of the sternum if advanced simultaneously. This concept is not new. ${ }^{15}$ The difference in our technique lies in preserving the humeral insertion of the pectoralis and central advancement with no additional muscle backcuts lateral to the thoracoacromial pedicle. This might explain why in some instances the procedure was done bilaterally to gain sufficient volume and 
medial advancement. It remains debatable whether a bilateral procedure preserving the humeral insertion would be superior to a unilateral one with humeral disinsertion.

In 3 cases local dehiscence in the skin flaps of the sutured wounds necessitated conservative measures to heal. It might be attributed to greater tension applied on the skin flaps in contrast to the muscle flaps, which gathered with ease. However, these seem to represent superficial wound-related problems unrelated to exacerbation of mediastinal infection. It might also reflect the heavily inflamed and edematous nature of the wound environment at the time of surgical intervention. We believed that it might be justifiable in selected cases to perform wide surgical debridement of necrotic tissues, followed by muscle flap surgery simultaneously at early times of inflammation. ${ }^{16}$ Some have expressed an opinion to remove the infected area widely on the detection of infection and to subsequently perform flap operations immediately or within few days. ${ }^{17}$ Our procedure faced obvious limitations in debriding the skin flap in anticipation of primary closure of the wound edges.

The recurrence rate after flap reconstruction has been reported variably, depending on the literature, ${ }^{3,9,10-12,15-19}$ from $0 \%$ to $20 \%$. In our patients the recurrence rate was $11 \%$, which is relatively high. This might reflect the higher proportion of patients with type II and III mediastinitis in our series and incomplete debridement before flap coverage. We are retrospectively reminded that intraoperative decision in regard to the adequacy of surgical debridement takes precedence over any choice or method in flap reconstruction.

Fortunately, the patients with recurrence were completely cured by the second operation, redoing a unilateral conventional pectoralis major muscle advancement flap or a vertical rectus abdominis flap. After a thorough debridement of the residual focus of infection, the dead space could be filled, with additional advancement obtained through a conventional pectoralis flap on one side. When the defect is eccentric to the lower third of the sternum, the rectus was turned over for complete coverage when the internal thoracic artery was intact. Despite their use in the first operation, both the pectoralis major and the rectus abdominis muscles were equally available at the time of the second operation for added mobilization. This can be considered another advantage of the bipedicled muscle flap.

\section{Conclusion}

The pectoralis major-rectus abdominis bipedicled muscle flap can be an effective tool in the armamentarium of surgical procedures for the treatment of poststernotomy mediastinitis. Flap elevation is relatively easy and fast, and vascularity is robust unrelated to the internal thoracic artery and provides ample volume and reach to the central defect. Moreover, a bilateral procedure provides incremental mobility and volume without the need for resection of the humeral insertion of the pectoralis, and thus postsurgical complications can be reduced.

\section{References}

1. Sjogren J, Nilsson J, Gustafsson R, Malmsjo M, Ingemansson R. The impact of vacuum-assisted closure on long-term survival after poststernotomy mediastinitis. Ann Thorac Surg. 2005;80:1270-5.

2. Cowan KN, Teague L, Sue SC, Mahoney JL. Vacuum-assisted wound closure of deep sternal infection in high-risk patients after cardiac surgery. Ann Thorac Surg. 2005;80:2205-12.

3. El Oakley RM, Wright JE. Postoperative mediastinitis: classification and management. Ann Thorac Surg. 1996;61:1030-6.

4. Robicsek F. Postoperative sterno-mediastinitis. Am Surg. 2000;66: 184-92.

5. Shabat S, Gur E, Weiss J, Shafir R. Chest wall reconstruction for sternal wound infection after internal mammary and gastroepiploic coronary artery bypass. Plast Reconstr Surg. 1998;102:1771-2.

6. Sakamoto H, Fukuda I, Oosaka M, Nakata H. Risk factors and treatment of deep sternal infection after cardiac operation. Ann Thorac Cardiovasc Surg. 2003;9:226-32.

7. Mekontso-Dessap A, Kirsch M, Brun-Buisson C, Loisance D. Poststernotomy mediastinitis due to Staphylococcus aureus: comparison of methicillin-resistant and methicillin-susceptible cases. Clin Infect Dis. 2001;32:877-83.

8. Hirata N, Hatsuoka S, Amemiya A, Ueno T, Kosakai Y. New strategy for treatment of MRSA mediastinitis: one-stage procedure for omental transposition and closed irrigation. Ann Thorac Surg. 2003;76:2104-6.

9. Jones G, Jurkiewicz MJ, Bostwick J, Wood R, Bried JT, Culbertson J, et al. Management of the infected median sternotomy wound with muscle flaps. The Emory 20-year experience. Ann Surg. 1997;225:766-76.

10. Ringelman PR, Vander Kolk CA, Cameron D, Baumgartner WA, Manson PN. Long-term results of flap reconstruction in median sternotomy wound infections. Plast Reconstr Surg. 1994;93:1208-14.

11. Netscher DT, Eladoumikdachi F, Goodman CM. Rectus abdominis muscle flaps used successfully for median sternotomy wounds after ipsilateral internal mammary artery ligation. Ann Plast Surg. 2001;47: 223-8.

12. Weinzweig N, Yetman R. Transposition of the greater omentum for recalcitrant median sternotomy wound infections. Ann Plast Surg. 1995; 34:471-7.

13. Taylor GI, Minabe T. The angiosomes of the mammals and other vertebrates. Plast Reconstr Surg. 1992;89:181-215.

14. Russell RC, Feller AM, Elliott LF, Kucan JO, Zook EG. The extended pectoralis major myocutaneous flap: uses and indications. Plast Reconstr Surg. 1991;88:814-23.

15. Solomon MP, Granick MS. Bipedicle muscle flaps in sternal wound repair. Plast Reconstr Surg. 1998;101:356-60.

16. Jeevanandam V, Smith CR, Rose EA, Malm JR, Hugo NE. Single-stage management of sternal wound infections. J Thorac Cardiovasc Surg. 1990;99:256-62.

17. Brandt C, Alvarez JM. First-line treatment of deep sternal infection by a plastic surgical approach: superior results compared with conventional cardiac surgical orthodoxy. Plast Reconstr Surg. 2002;109:2231-7.

18. Pairolero PC, Arnold PG, Harris JB. Long-term results of pectoralis major muscle transposition for infected sternotomy wounds. Ann Surg. 1991;213:583-90.

19. Yoo YC, Chung SI, Yang WY, Park J. Treatment of acute sterno-mediastinitis using regional muscle flaps. J Korean Soc Plast Reconstr Surg. 2003;30:345-51. 